\title{
Identification of Intrinsic Active Sites for the Selective Catalytic Reduction of Nitric Oxide on Metal-Free Carbon Catalysts via Selective Passivation
}

\author{
Jin Yuan ${ }^{1}$, JinXing Mi², Rongqiang Yin ${ }^{1}$, Tao $\mathrm{Yan}^{1}$, Hao Liu ${ }^{1}$, Xiaoping Chen ${ }^{1}$, Jun Liu ${ }^{3}$, Wenzhe \\ $\mathrm{Si}^{1}$, Yue Peng ${ }^{1}$, Jianjun Chen ${ }^{1 *}$, and Junhua $\mathrm{Li}^{1 *}$ \\ ${ }^{1}$ State Key Joint Laboratory of Environment Simulation and Pollution Control, School of Environment, Tsinghua \\ University, Beijing, 100084, PR China \\ ${ }^{2}$ State Key Laboratory of Catalysis, Dalian Institute of Chemical Physics, Chinese Academy of Sciences, Dalian, \\ 116023, PR China. \\ ${ }^{3}$ College of Chemistry and Chemical Engineering, Taiyuan University of Technology, Taiyuan, 030024, PR China. \\ *Corresponding author: chenjianjun@tsinghua.edu.cn; lijunhua@tsinghua.edu.cn
}

\begin{abstract}
Although carbon catalysts have been commercialized for low-temperature selective catalytic reduction (SCR) of $\mathrm{NO}$ with $\mathrm{NH}_{3}$ for decades, the nature of the active sites remains unclear. Herein we design a proof-ofconcept study to directly evidence that the nucleophilic ketonic carbonyl groups are the intrinsic SCR active sites on metal-free carbon catalysts through ex situ and in situ selective passivation strategies. The turnover frequency (TOF) of ketonic carbonyl group was provided and the structure-reactivity relationship was established for the first time. Density functional theory calculations combined with in situ spectroscopy revealed the standard carbon-catalyzed $\mathrm{SCR}$ reaction involves a redox cycle of ketonic carbonyl/phenol $(\mathrm{C}=\mathrm{O} / \mathrm{C}-\mathrm{OH})$ pairs, during which the activation of $\mathrm{NH}_{3}$ is the rate-limiting step. This work identifies the intrinsic SCR active sites and advances the metal-free carbon catalysis. As a further step, the carbon catalysts demonstrate analogous mechanistic features with vanadyl catalysts, opening up the possibility to parallel the SCR mechanisms on metal-free carbon catalysts to those on transition metal catalysts at the atomic scale.
\end{abstract}




\section{Experimental Procedures}

Catalysts Preparation. All the chemicals were purchased from Aladdin without further purification. Commercial nanotubes (CNTs) were obtained from Chengdu organic chemicals, Chinese academy of sciences. The outer diameter, wall thickness, and length of CNTs are $10-15 \mathrm{~nm}, 2-5 \mathrm{~nm}$, and 3-5 $\mu \mathrm{m}$, respectively. The pristine CNTs was firstly pretreated in concentrated $\mathrm{HCl}$ to remove metal impurities, and then annealed at $1100^{\circ} \mathrm{C}$ for $2 \mathrm{~h}$ to get a well graphitized form. Subsequently, the annealed sample was refluxed in concentrated $\mathrm{HNO}_{3}$ for $3 \mathrm{~h}$ to functionalize the surface with oxygen-containing functional groups. In order to regulate the type and content of oxygen-containing functional groups, the oCNTs was further annealed at $700,800,900$, and $1000^{\circ} \mathrm{C}$ under argon atmosphere for $2 \mathrm{~h}$, and the products were labeled as oCNTs-700, oCNTs-800, oCNTs-900, and oCNTs-1000, respectively. Moreover, the pretreatment, oxidation, and annealing procedures were also conducted in a commercial activated carbon (AC, Xinhua Chemical Plant, PR China.) to confirm the identical role of ketonic $\mathrm{C}=\mathrm{O}$ in $\mathrm{NH}_{3}-\mathrm{SCR}$ reaction. The samples in that case were named as oAC, oAC-700, oAC-800, oAC-900, and oAC-1000, respectively.

Selective passivation of ketonic $\mathrm{C}=\mathrm{O}$ groups. In this study, phenylhydrazine $(\mathrm{PH})$ was applied to passivate ketonic carbonyl groups of CNTs because PH can react with ketonic carbonyl groups with producing hydrazones in higher than $99.9 \%$ under mild conditions (Scheme S2). ${ }^{1-5}$ Typically, $2 \mathrm{~mL}$ PH was dissolved in $100 \mathrm{~mL}$ ethanol and $1 \mathrm{~g}$ oCNTs was added into the solution. After stirring for $72 \mathrm{~h}$ at room temperature, the mixed solution was filtered, and then the precipitate was washed with $2 \mathrm{~L}$ ethanol to remove the physical adsorbed PH. Finally, the precipitate was dried in a vacuum at $80^{\circ} \mathrm{C}$ for $24 \mathrm{~h}$. The obtained CNTs derivative was donated as oCNTs-PH (oCNTs-700-PH). The selective passivation process was also conducted in oAC, and the products was named as oAC-PH.

Quantification of ketonic carbonyl groups. Owning to the quantifiability of the reaction between phenylhydrazine and ketonic $\mathrm{C}=\mathrm{O}$ groups, the $\mathrm{PH}$ derivatization in conjunction with X-ray photoelectron spectroscopy (XPS) was usually applied to quantify the content of ketonic carbonyl groups.-8 In this study, the increase in the content of $\mathrm{N}$ after $\mathrm{PH}$ passivation was further used to measure the surface content of ketonic $\mathrm{C}=\mathrm{O}$ groups according to the reaction stoichiometry. The spectral deconvolution of XPS was also avoided in this process. By normalizing the specific surface area of the CNTs, the concentration of ketonic carbonyl group $\left(\mathrm{C}=\mathrm{O}\right.$ sites $\left.\mathrm{nm}^{-2}\right)$ was obtained.

In situ selective passivation of ketonic $\mathrm{C}=\mathrm{O}$ groups. The in situ selective passivation of ketonic $\mathrm{C}=\mathrm{O}$ groups was performed in a fixed bed reactor system. The concentration of $\mathrm{PH}$ was continuously measured by gas chromatography (7890A, Agilent). The liquid-phase phenylhydrazine, which was used as titration agent to selectively passivate ketonic $\mathrm{C}=\mathrm{O}$ groups, was introduced by a vaporizer and premixed with $\mathrm{O}_{2}, \mathrm{~N}_{2}, \mathrm{NH}_{3}$, and $\mathrm{NO}$ in the gas mixing system. The independent experiments without catalysts were performed to determine if there are side reactions between the titrant $\mathrm{PH}$ and reactants $\mathrm{NO}, \mathrm{O}_{2}$ or $\mathrm{NH}_{3}$. As shown in Figure $\mathrm{S} 10$, we flowed $\mathrm{NO}, \mathrm{NH}_{3}$, and $\mathrm{O}_{2}$ to the reaction system at $200{ }^{\circ} \mathrm{C}$. Then, the titrant $\mathrm{PH}$ was added to the feeds. The introduction of $\mathrm{PH}$ had negligible effects on the concentration of $\mathrm{NO}, \mathrm{NH}_{3}$, and $\mathrm{O}_{2}$. Moreover, the concentration of $\mathrm{PH}$ also kept a stable value after $1 \mathrm{~h}$. The results show that there are no significant side reactions between the titrant and SCR reactants under the chosen reaction conditions.

Catalytic performance test. The SCR performance of the carbon catalysts was tested in a reactor system. The feed gas consisted of $500 \mathrm{ppm} \mathrm{NO}, 500 \mathrm{ppm} \mathrm{NH}_{3}, 5 \mathrm{vol} \% \mathrm{O}_{2}$, and balance $\mathrm{N}_{2}$. The total flow rate was $100 \mathrm{~mL} \mathrm{~min}^{-1}$. The outlet gas was analyzed by an IR spectrometer (Multigas 2030HS, MKS). In a typical procedure, the test maintained for $2 \mathrm{~h}$ at desired temperature to reach steady state. Reaction rate was measured by adjusting the amount of carbon catalyst for NO conversion to below $20 \%$.

The $\mathrm{NO}_{\mathrm{x}}$ conversion rate and $\mathrm{N}_{2}$ selectivity were calculated according to the following equations:

$$
\begin{gathered}
\mathrm{NO}_{\mathrm{x}}=\frac{\left(\mathrm{NO}_{x}\right)_{\text {in }}-\left(\mathrm{NO}_{x}\right)_{\text {out }}}{\left(\mathrm{NO}_{\mathrm{x}}\right)_{\text {in }}} \times 100 \% \\
\mathrm{~N}_{2} \text { selectivity }=\frac{\left(\mathrm{NO}_{\mathrm{x}}\right)_{\text {in }}+\left(\mathrm{NH}_{3}\right)_{\text {in }}-\left(\mathrm{NO}_{\mathrm{x}}\right)_{\text {out }}-\left(\mathrm{NH}_{3}\right)_{\text {out }}-2\left(\mathrm{~N}_{2} \mathrm{O}\right)_{\text {out }}}{\left(\mathrm{NO}_{\mathrm{x}}\right)_{\text {in }}+\left(\mathrm{NH}_{3}\right)_{\text {in }}-\left(\mathrm{NO}_{\mathrm{x}}\right)_{\text {out }}-\left(\mathrm{NH}_{3}\right)_{\text {out }}} \times 100 \%
\end{gathered}
$$


Catalyst characterization. $\mathrm{N}_{2}$ adsorption/desorption experiments were performed on a micromeritics ASAP 2460 instrument. Before the tests, the samples were degassed at $150^{\circ} \mathrm{C}$ for $12 \mathrm{~h}$. The specific surface aera was determined by using the Brunauer-Emmett-Teller (BET) equation. Total pore volumes were calculated from the $\mathrm{N}_{2}$ adsorption amount at a relative pressure of about 0.995 . Temperature programmed desorption experiments were performed on a chemisorption analyzer (Micromeritics, AutoChem 2920 Thermostar) equipped with a quadrupole mass spectrometer. Typically, the sample of $100 \mathrm{mg}$ was annealed to $1273 \mathrm{k}$ under the flowing helium $\left(50 \mathrm{~mL} \mathrm{~min}{ }^{-1}\right)$ at a rate of $10^{\circ} \mathrm{C} \mathrm{min}{ }^{-1}$. The relative amount of $\mathrm{CO}$ and $\mathrm{CO}_{2}$ released was determined by MS signal. XPS spectra analysis

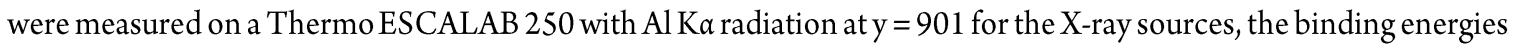
were calibrated using the $\mathrm{C} 1 \mathrm{~s}$ peak at $284.8 \mathrm{eV}$. In situ diffused reflectance infrared Fourier transform spectroscopy (in situ DRIFTS) was conducted on NICOLET 6700 FT-IR spectrometer (Thermo Fisher, USA) with a Harrick IR cell. The total gas flow used in this process is $50 \mathrm{~mL} / \mathrm{min}$. Quasi in situ X-ray photoelectron spectroscopy (quasi in situ XPS) measurements were performed on a SPECS XPS system. All spectra were obtained with using monochromatized $\mathrm{Al} \mathrm{Ka}$ irradiation at $1486.6 \mathrm{eV}$ generated by an $\mathrm{Al}$ anode (SPECS XR-50) and an excitation source power $(150 \mathrm{~W})$. The total gas flow used in this process is $50 \mathrm{~mL} / \mathrm{min}$, and the used $\mathrm{NH}_{3}, \mathrm{NO}$ and $\mathrm{O}_{2}$ are $1 \%, 1 \%$, and $10 \%$, respectively. Transmission electron microscope (TEM) images were observed on a JEOL $2100 \mathrm{~F}$ at $200 \mathrm{kV}$. Raman spectra was measured using a Raman microscope array detector (Horiba LaRAM HR Evolution, Horiba Jobin Yvon) with an excitation laser beam wavelength of $532 \mathrm{~nm}$.

DFT Calculations. All the spin-polarized density functional theory (DFT) calculations were performed by using Vienna Ab-initio Simulation Package (VASP) under the Projected Augmented Wave (PAW) method. The PerdewBurke-Ernzerhof (PBE) functional was used to describe the exchange and correlation effects. ${ }^{9}$ For all the geometry optimizations, $400 \mathrm{eV}$ was chosen as the cutoff energy of the plane-wave basis to ensure the precision of calculations. A $2 \times 1 \times 1$ Monkhorst-Pack grids was used to carry out the surface calculations on all the models. At least $15 \AA$ vacuum layer was applied in z-direction of the slab models to prevent the vertical interactions between slabs. ${ }^{10,11}$ The convergence thresholds for structural optimization were set at $0.02 \mathrm{eV} / \AA$ in force. The convergence criterion for energy is $10^{-5} \mathrm{eV}$. The van der Waals dispersion by employing the $\mathrm{D} 3$ method of Grimme was considered for all the calculation. ${ }^{12}$ The CI-NEB was applied for computing energy barriers, which can obtain the minimum energy path between the given initial and final positions. The convergence thresholds for transition state search were set at 0.05 $\mathrm{eV} / \AA$ in force. The convergence criterion for energy is $10^{-4} \mathrm{eV}$. The adsorption energy of gas molecules on the surface of ketonic carbonyl group model were calculated by the following formula:

$$
\mathrm{E}_{\mathrm{a}}=\mathrm{E}_{\text {gas-carbon }}-\mathrm{E}_{\text {gas }}-\mathrm{E}_{\text {carbon }}
$$

\section{Results and Discussion}
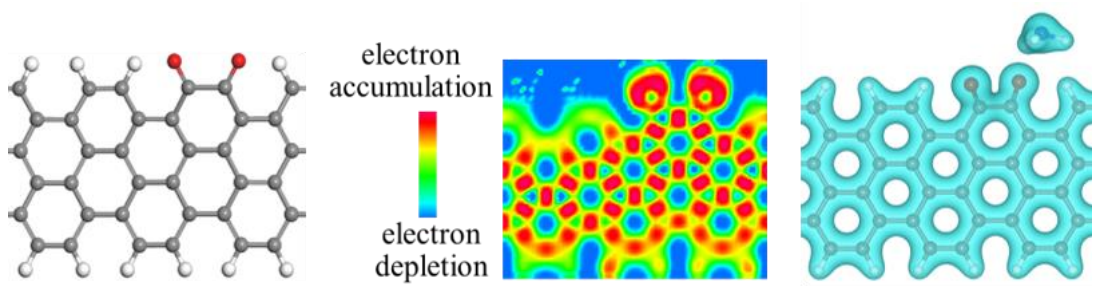

Figure S1. The nucleophilicity feature of ketonic carbonyl groups. 


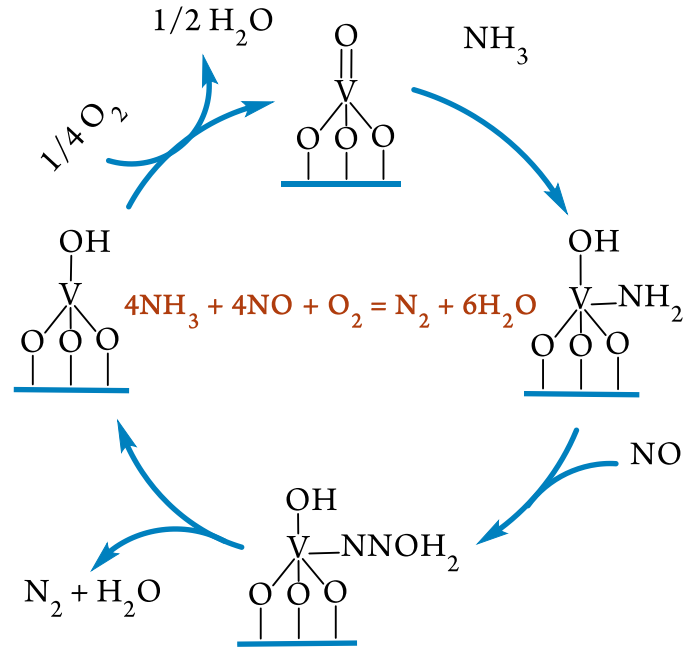

Scheme S1. Representative reaction mechanism of standard $\mathrm{NH}_{3}$-SCR on vanadyl catalysts. ${ }^{9,13-17}$

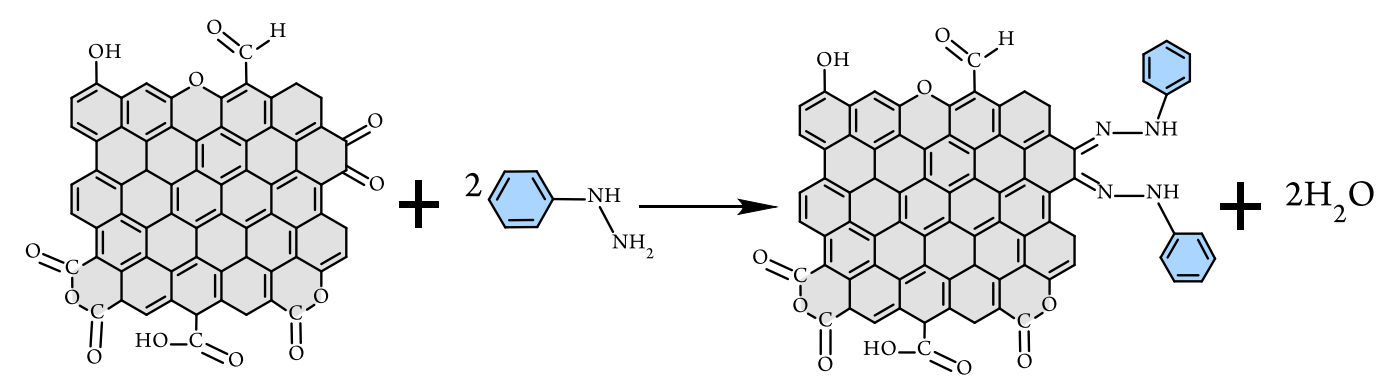

Scheme $\mathrm{S} 2$. The passivation process for ketonic $\mathrm{C}=\mathrm{O}$ groups. 


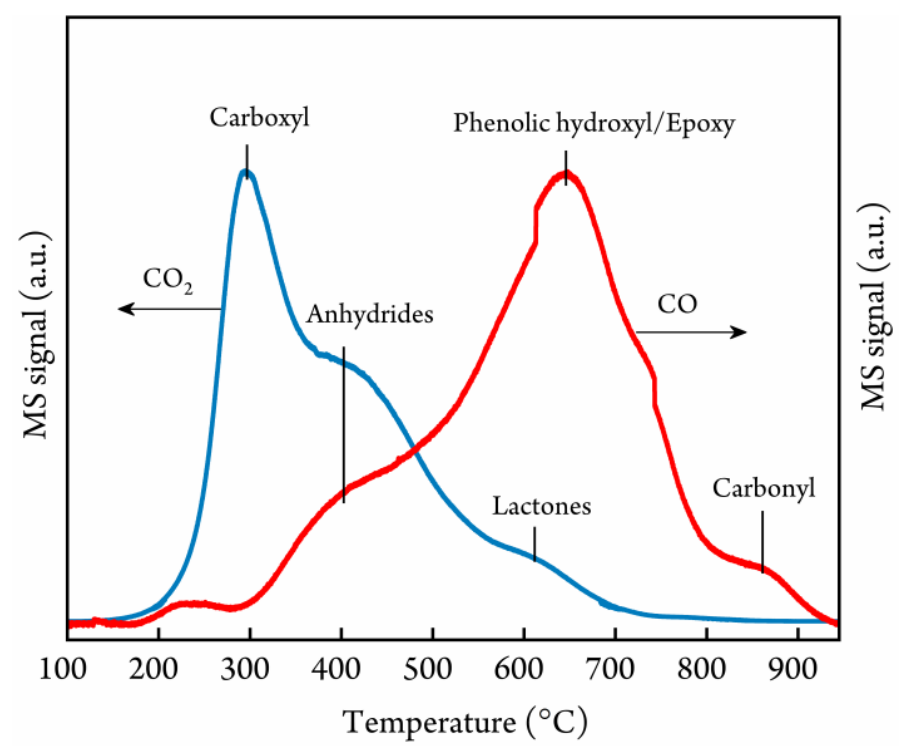

Figure S2. CO and $\mathrm{CO}_{2}$ signal of TPD spectra for the oCNTs.
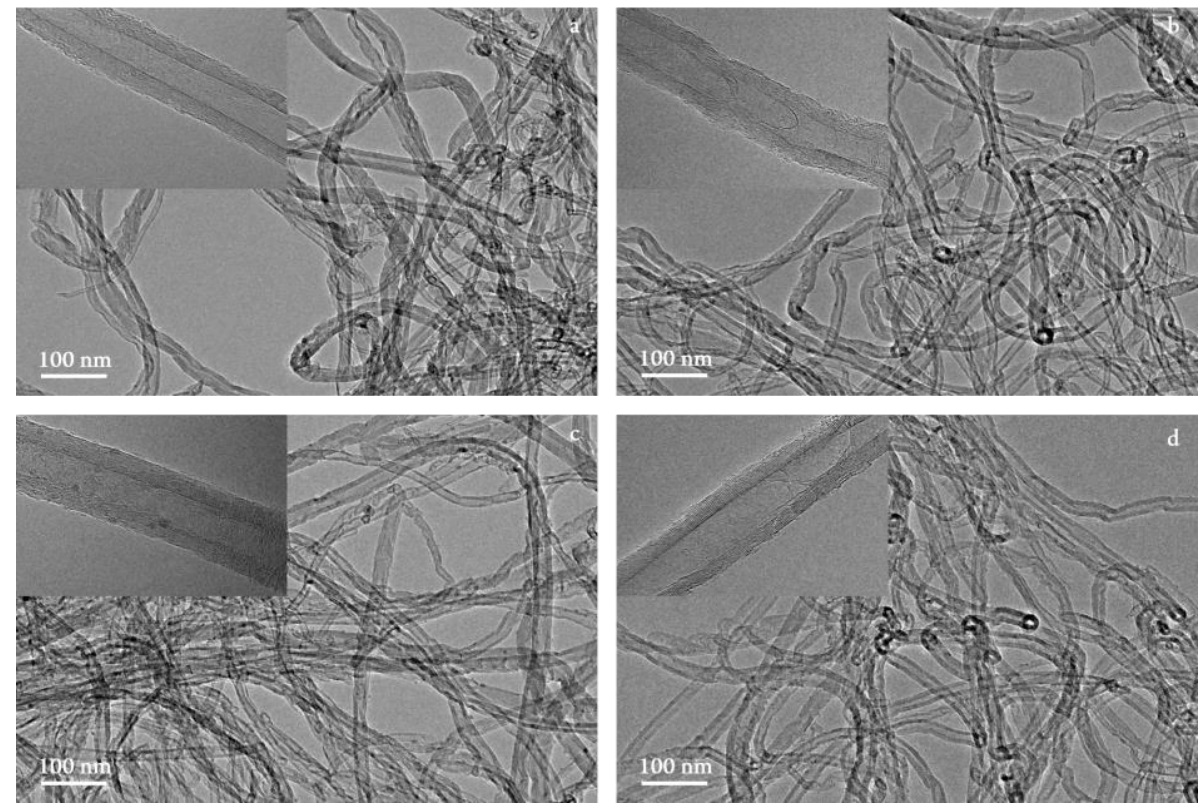

Figure S3. TEM images of the CNTs and CNTs with passivated ketonic $\mathrm{C}=\mathrm{O}$ groups. a, b, c, and d are the typical pictures of the oCNTs, oCNTs-PH, oCNTs-700, and oCNTs-700-PH, respectively. 


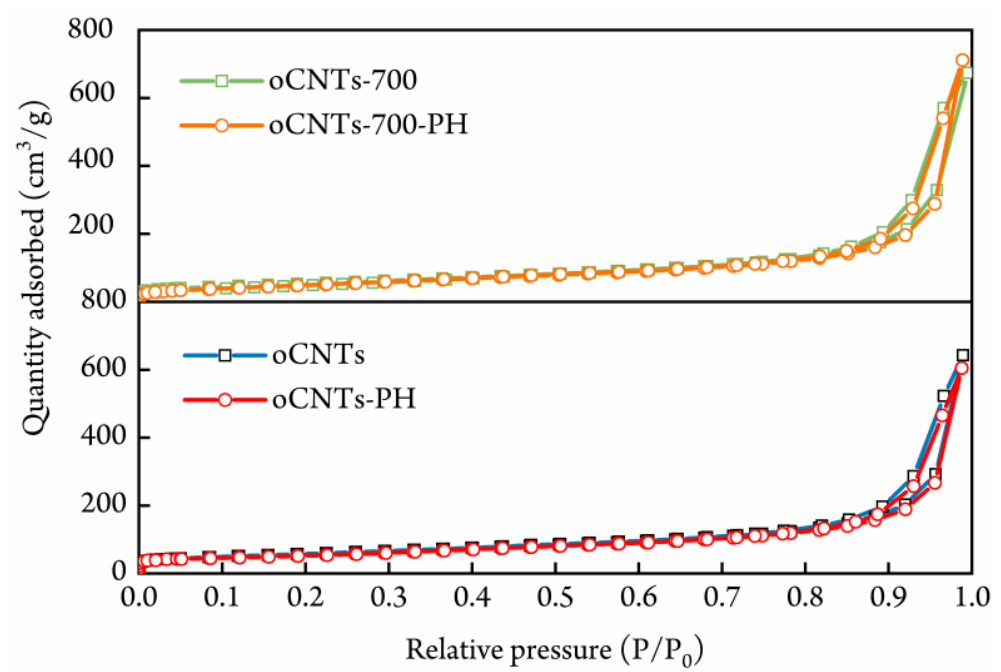

Figure S4. $\mathrm{N}_{2}$ adsorption isotherms of the oCNTs, oCNTs-PH, oCNTs-700, and oCNTs-700-PH.

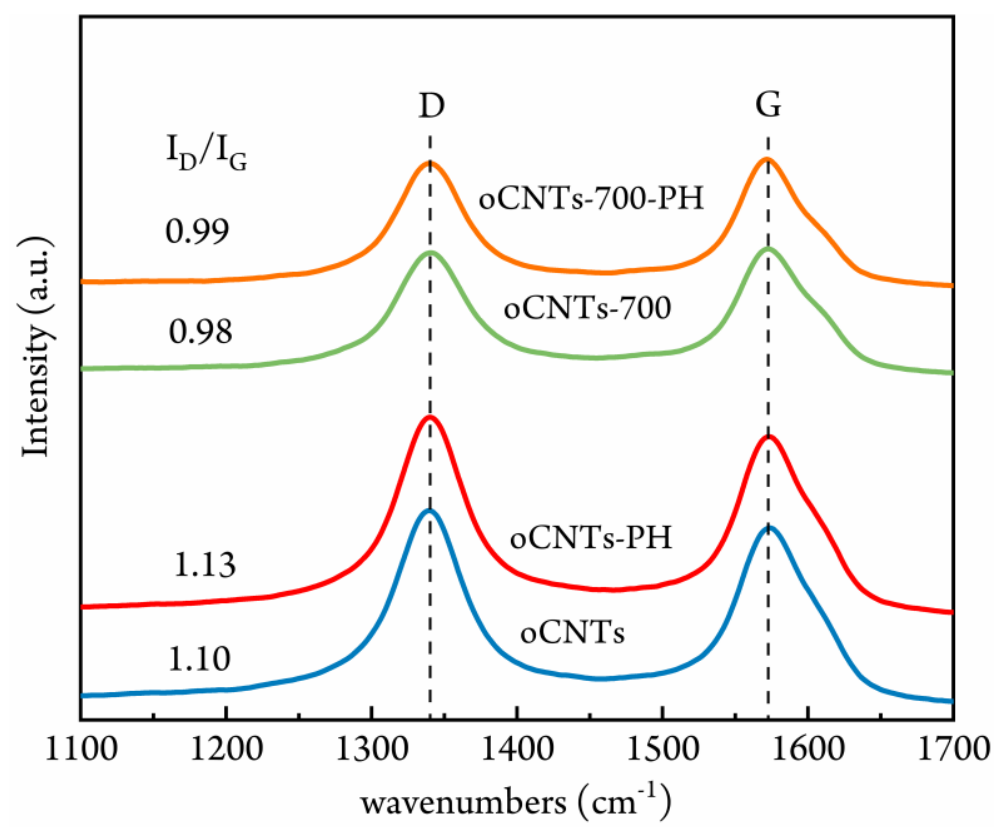

Figure S5. Raman spectra of the oCNTs, oCNTs-PH, oCNTs-700, and oCNTs-700-PH. 
a

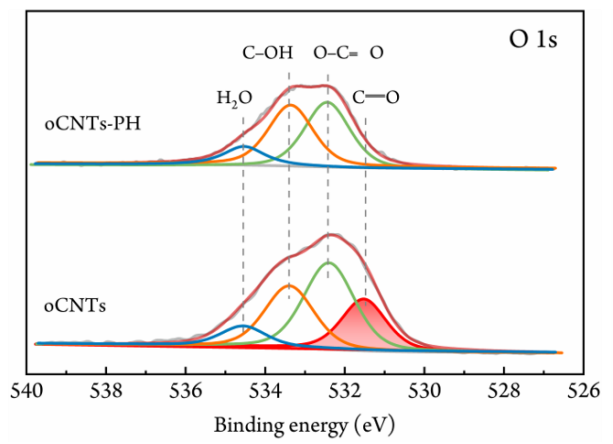

b

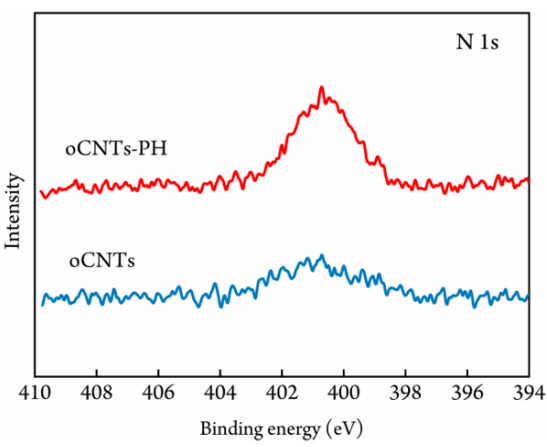

Figure S6. O 1s (a) and N 1s (b) XPS spectra of the oCNTs and oCNTs-PH.

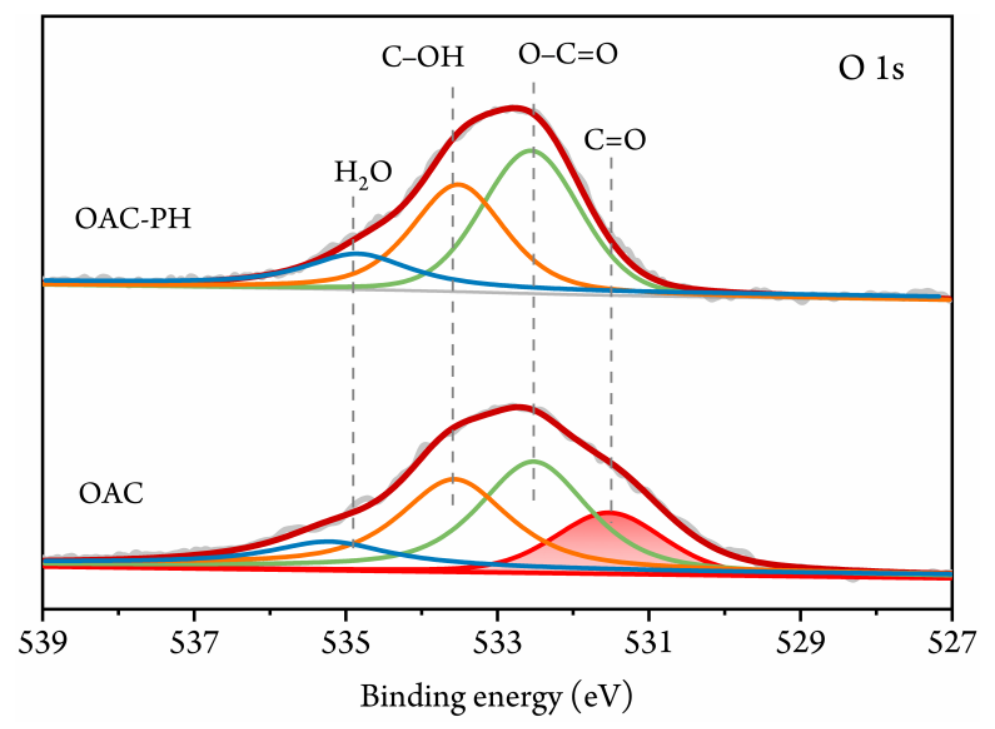

Figure S7. O 1s XPS spectra of the OAC and OAC-PH. 


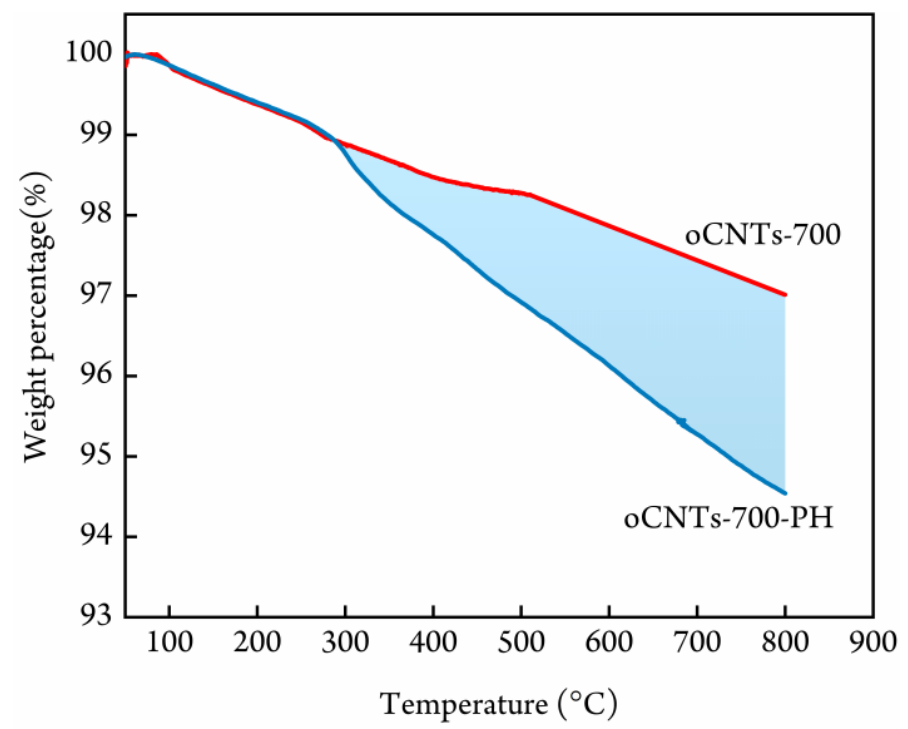

Figure S8. TGA curves of the oCNTs-700 and oCNTs-700-PH.

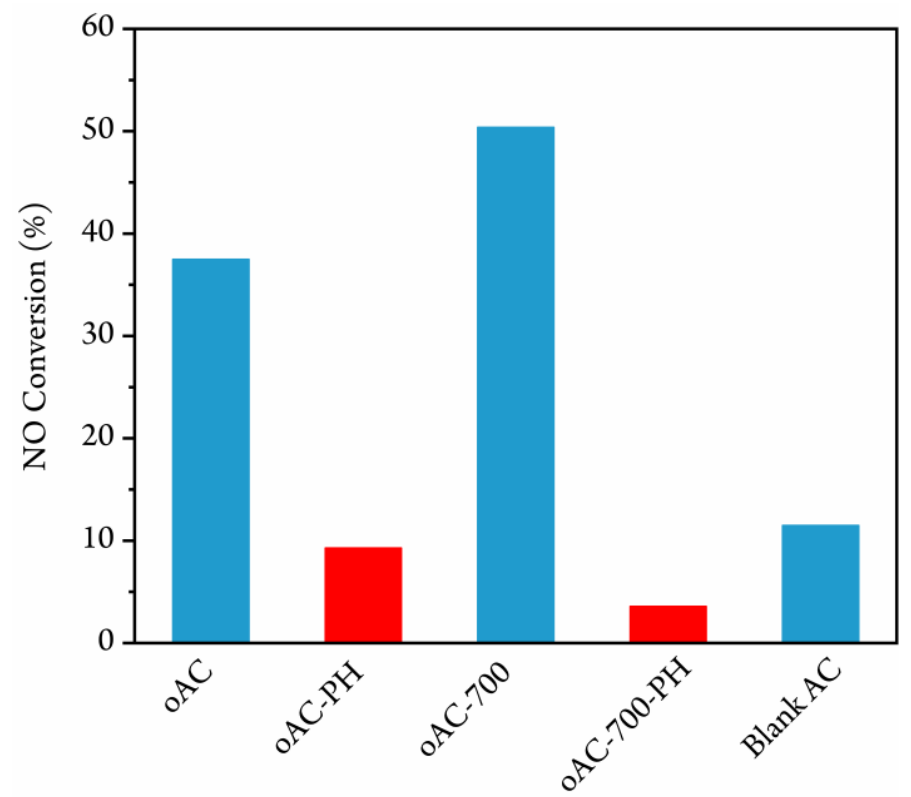

Figure $\mathrm{S9} . \mathrm{NH}_{3}-\mathrm{SCR}$ activity of the oAC and oAC-PH at $180^{\circ} \mathrm{C}$. 

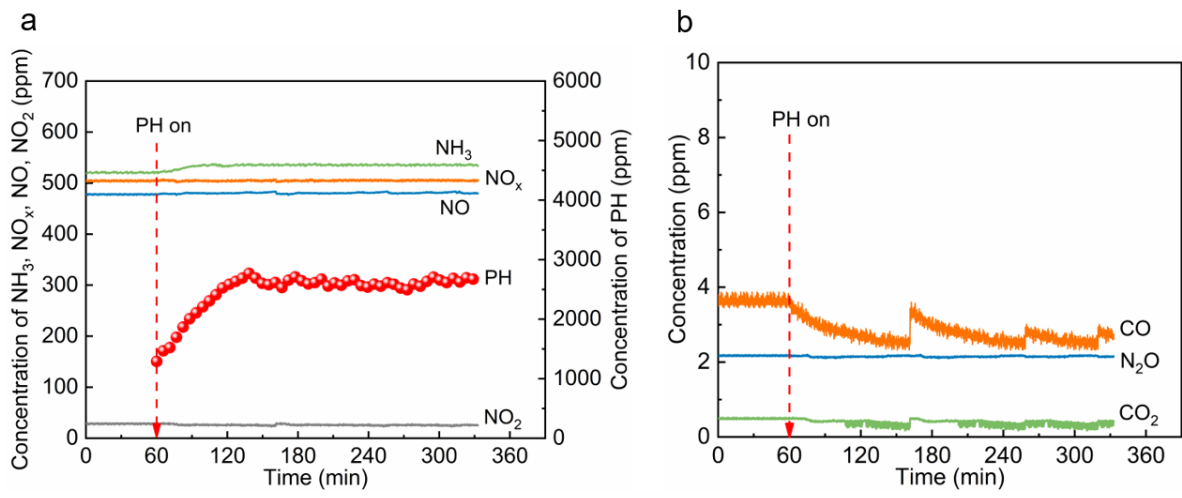

Figure S10. Gas concentration at $200^{\circ} \mathrm{C}$. (a) Concentration of $\mathrm{NH}_{3}, \mathrm{NO}_{\mathrm{x}}, \mathrm{NO}, \mathrm{NO}_{2}$, and $\mathrm{PH}$. (b) Concentration of $\mathrm{CO}_{2}, \mathrm{~N}_{2} \mathrm{O}$, and $\mathrm{CO}$.

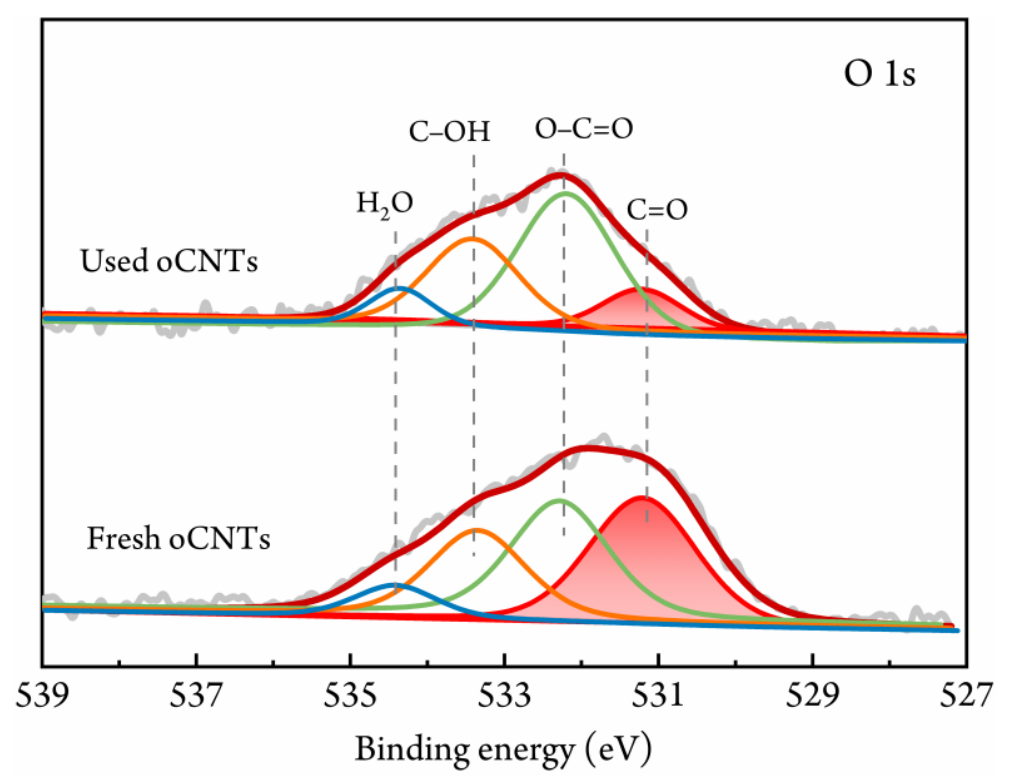

Figure S11. O 1s XPS spectra of the fresh and used oCNTs. 


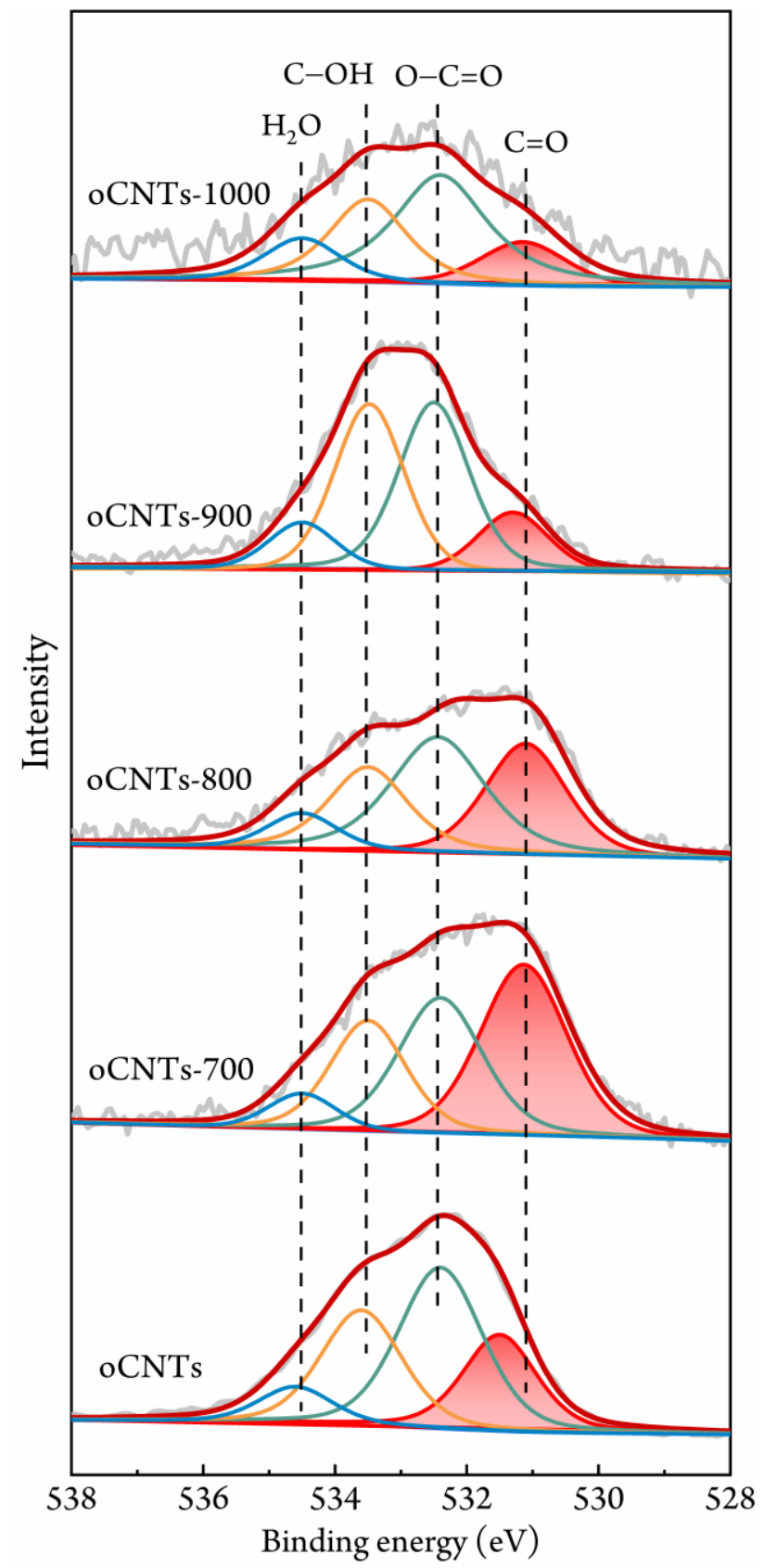

Figure S12. O 1s XPS spectra of oCNTs and annealed oCNTs.

The peak at $531.5 \mathrm{eV}$ of oCNTs was assigned to ketonic carbonyl groups. After annealing treatment, the binding energies shifted to the lower positions $(531.0 \pm 0.1 \mathrm{eV})$ because the conjugated form of ketonic carbonyl groups (diketone and quinone) increased. ${ }^{18,19}$ 


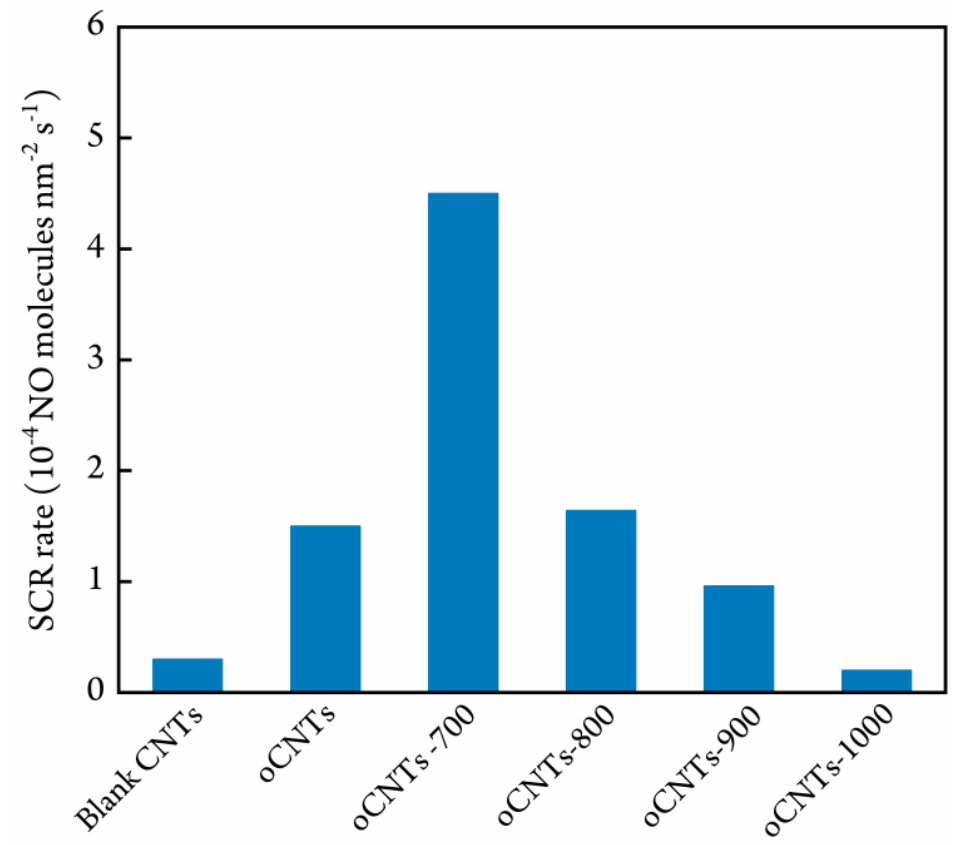

Figure S13. $\mathrm{NH}_{3}-\mathrm{SCR}$ activity of the oCNTs catalysts at $200^{\circ} \mathrm{C}$.

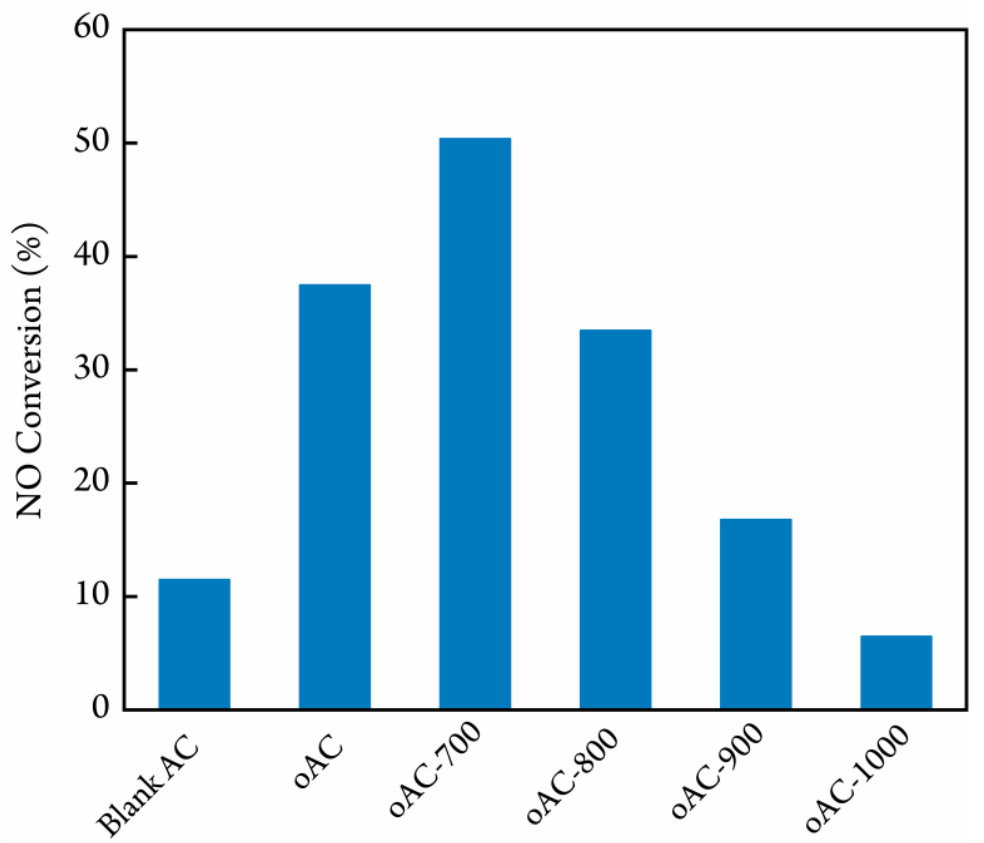

Figure S14. $\mathrm{NH}_{3}$-SCR activity of the oAC catalysts at $180^{\circ} \mathrm{C}$. 


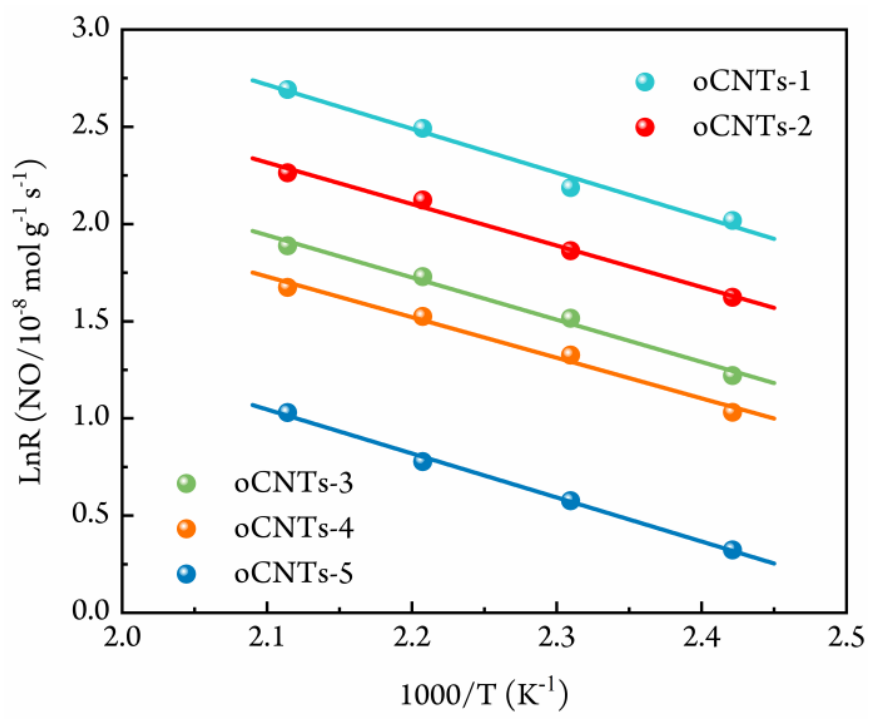

Figure S15. Arrhenius plots for the oCNTs catalysts.

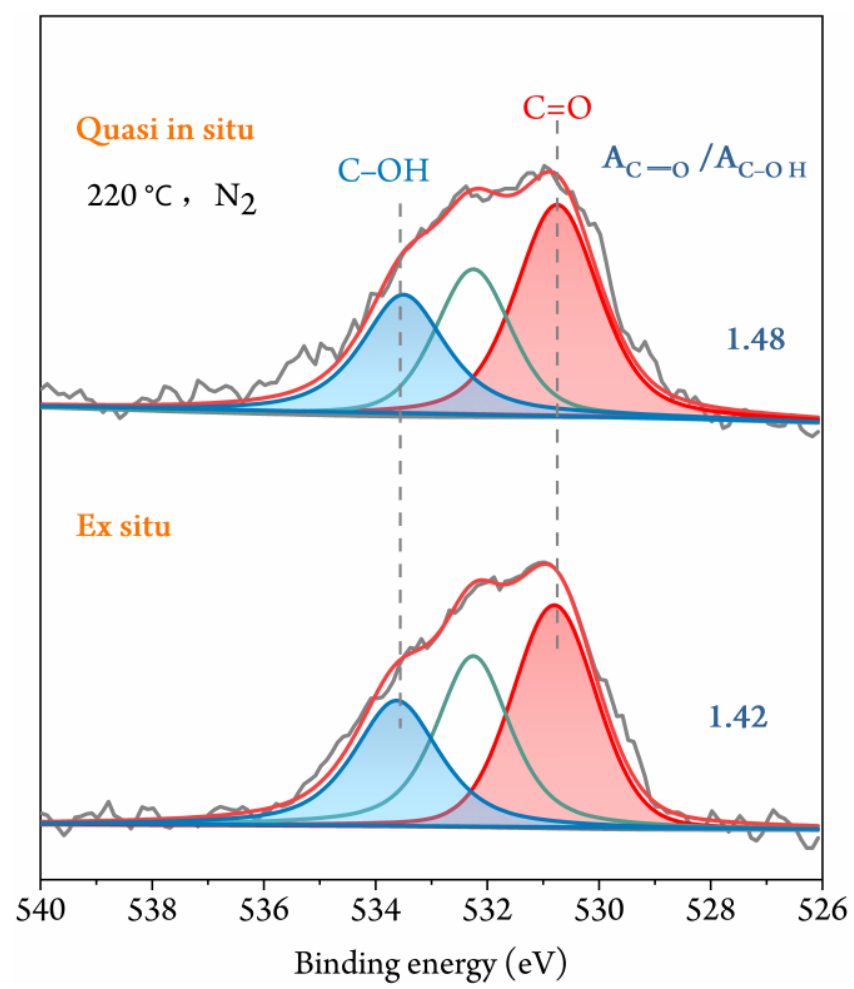

Figure S16. Quasi-in situ and ex situ O 1s XPS spectra of oCNTs-700. 

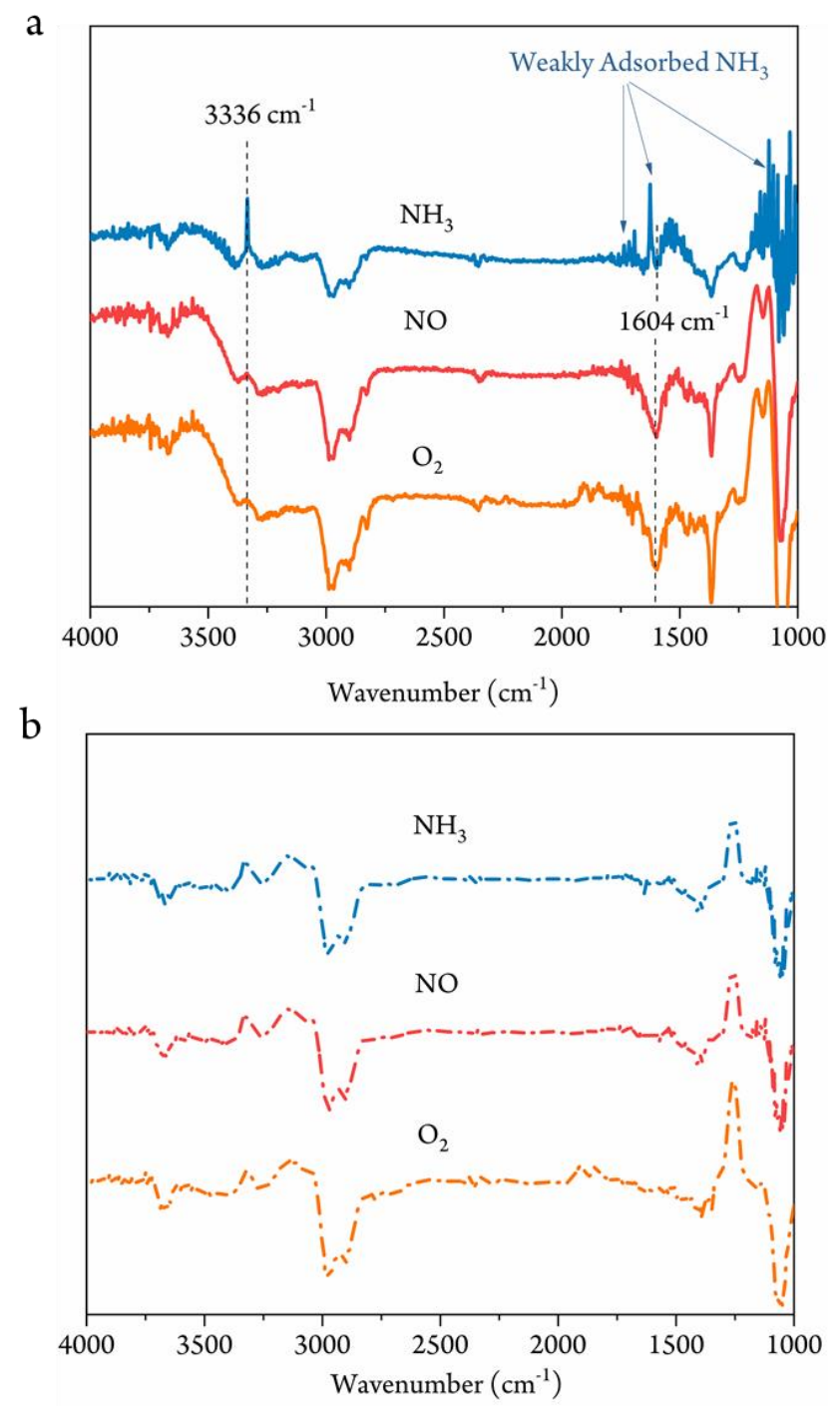

Figure S17. In situ DRIFT spectra after $1000 \mathrm{ppm} \mathrm{NH}_{3}$ adsorption (30 min) followed by $1000 \mathrm{ppm} \mathrm{NO}$ (30 min) and $10 \% \mathrm{O}_{2}(30 \mathrm{~min})$ addition. a. oCNTs- $700+\mathrm{KBr}$; b. KBr.

The in situ DRIFTS was conducted under the similar reaction conditions to that in fixed bed reactor, and the oCNTs700 catalyst $(2 \mathrm{mg})$ mixed with $\mathrm{KBr}(200 \mathrm{mg})$ was used as the represented samples. The DRIFTS spectra of comparison were also obtained by using pure $\mathrm{KBr}$. First, the samples were heated to $220^{\circ} \mathrm{C}$ for $30 \mathrm{~min}$ and cooled to $180^{\circ} \mathrm{C}$ for 30 min under $\mathrm{He}$ atmosphere in the IR chamber. Then, the $1000 \mathrm{pm} \mathrm{NH}_{3}, 1000 \mathrm{ppm} \mathrm{NO}$, and $10 \% \mathrm{O}_{2}$ were introduced in order. Combined with quasi-in situ O 1s XPS (Figure 4), the peaks at $1604 \mathrm{~cm}^{-1}$ could be assigned as $\mathrm{O}-\mathrm{C}=\mathrm{O}$ vibrations. The IR peaks at $3336 \mathrm{~cm}^{-1}$ are the signal of $\mathrm{N}-\mathrm{H}$ vibrations in adsorbed ammonia species, which disappeared after introducing NO, thus reflecting the occurrence of $\mathrm{NO}$ reacting with activated ammonia species over carbon surface. 


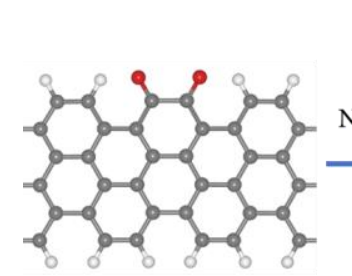

A

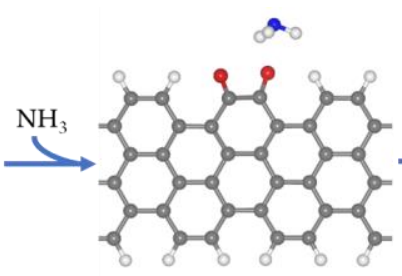

B

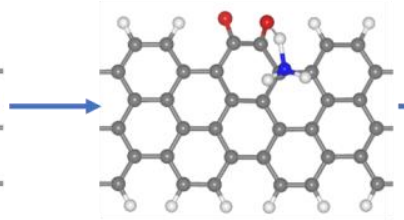

TS1

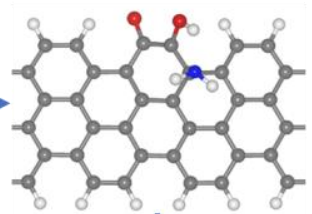

$\mathrm{C}{ }^{\mathrm{NO}}$

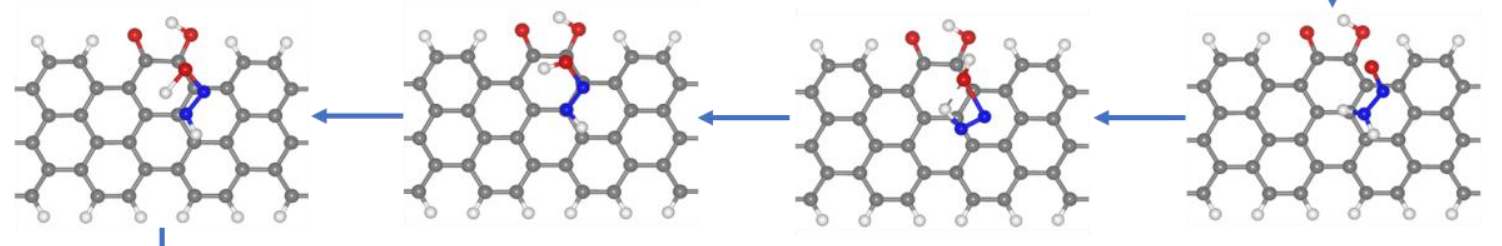

D

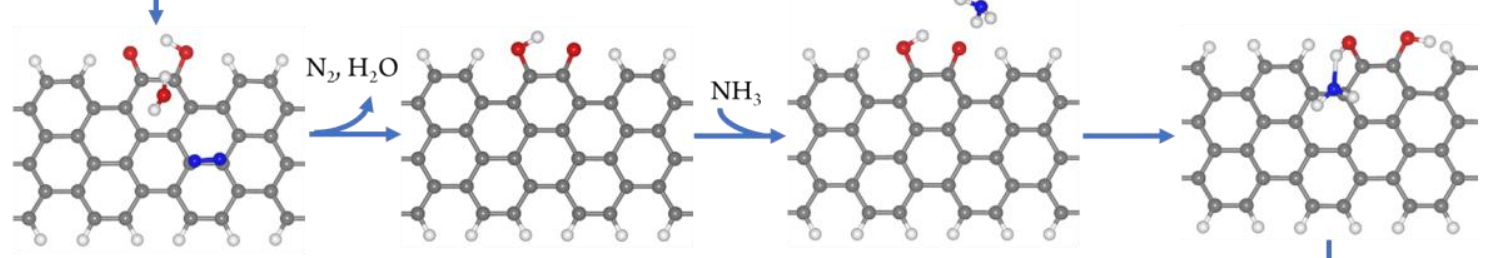

F

G

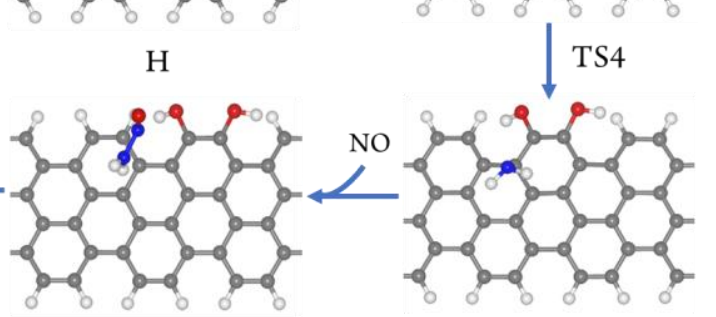

K

$\mathrm{J}$

I

TS5
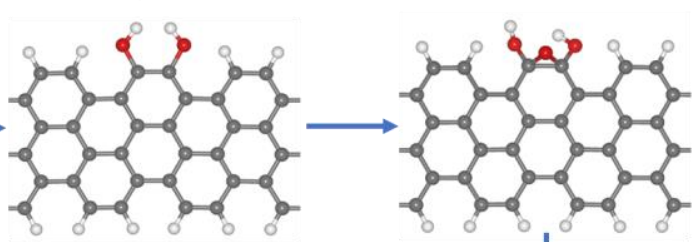

L

$\mathrm{M}$

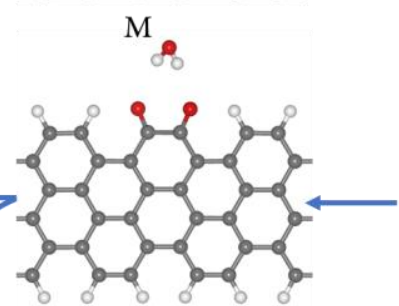

O

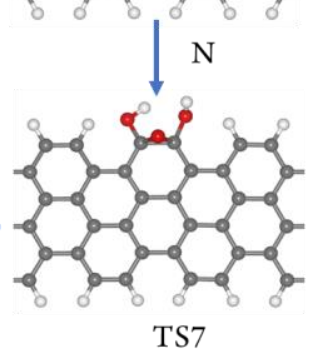

TS7

A

Figure S18. Optimized structures of the reactants, transition states, intermediate, and product for all elementary steps in the $\mathrm{NH}_{3}-\mathrm{SCR}$ routes over ketonic $\mathrm{C}=\mathrm{O}$ groups. Black, red, blue, and white balls denote $\mathrm{C}, \mathrm{O}, \mathrm{N}$, and $\mathrm{H}$ atoms, respectively. 
Table S1. The surface area and pore volume of samples.

\begin{tabular}{ccc}
\hline Catalysts & Total pore volume $\left(\mathrm{cm}^{3} / \mathrm{g}\right)$ & Surface area $\left(\mathrm{m}^{2} / \mathrm{g}\right)$ \\
\hline oCNTs & 1.05 & 206 \\
oCNTs-PH & 1.03 & 203 \\
oCNTs-700 & 1.18 & 219 \\
oCNTs-700-PH & 1.13 & 225 \\
oCNTs-800 & 1.26 & 248 \\
oCNTs-900 & 1.32 & 265 \\
oCNTs-1000 & 1.39 & 280 \\
\hline
\end{tabular}

Table S2. Calculated results for the adsorption of $\mathrm{NH}_{3}$ and $\mathrm{NO}$ on ketonic carbonyl group.

\begin{tabular}{ccc}
\hline Configuration & $\mathrm{E}_{\text {ads }}(\mathrm{eV})$ & $\mathrm{R}(\AA)$ \\
\hline $\mathrm{NH}_{3} / \mathrm{C}=\mathrm{O}-\mathrm{GP}$ & -0.36 & 2.3 \\
$2 \mathrm{NH}_{3} / 2 \mathrm{C}=\mathrm{O}-\mathrm{GP}$ & -1.33 & $2.1 / 2.0$ \\
$\mathrm{NO} / \mathrm{C}=\mathrm{O}-\mathrm{GP}$ & 1.95 & $\mathrm{NC}$ \\
$2 \mathrm{NO} / 2 \mathrm{C}=\mathrm{O}-\mathrm{GP}$ & 3.95 & $\mathrm{NC}$ \\
\hline
\end{tabular}

NC stood for "not calculated".

\section{References}

(1) Sutherland, I.; Sheng, E.; Brewis, D. M.; Heath, R. J., Studies of Vapor-Phase Chemical Derivatization for XPS Analysis Using Model Polymers. J. Mater. Chem. 1994, 4 (5), 683-687.

(2) Xing, Y.; Dementev, N.; Borguet, E., Chemical Labeling for Quantitative Characterization of Surface Chemistry. Current Opin. Solid State Mater. 2007, 11 (5-6), 86-91.

(3) Langley, L. A.; Villanueva, D. E.; Fairbrother, D. H., Quantification of Surface Oxides on Carbonaceous Materials. Chem. Mater. 2006, 18 (1), 169-178.

(4) Wepasnick, K. A.; Smith, B. A.; Bitter, J. L.; Fairbrother, D. H., Chemical and Structural Characterization of Carbon Nanotube Surfaces. Anal. Bioanal. Chem. 2010, 396 (3), 1003-1014.

(5) Dementev, N.; Feng, X.; Borguet, E., Fluorescence Labeling and Quantification of Oxygen-Containing Functionalities on the Surface of Single-Walled Carbon Nanotubes. Langmuir 2009, 25 (13), 7573-7577.

(6) Qi, W.; Liu, W.; Zhang, B.; Gu, X.; Guo, X.; Su, D., Oxidative Dehydrogenation on Nanocarbon: Identification and Quantification of Active Sites by Chemical Titration. Angew. Chem. Int. Ed. 2013, 52 (52), 14224-14228.

(7) Qi, W.; Liu, W.; Guo, X.; Schloegl, R.; Su, D., Oxidative Dehydrogenation on Nanocarbon: Intrinsic Catalytic Activity and Structure-Function Relationships. Angew. Chem. Int. Ed. 2015, 54 (46), 13682-13685.

(8) Hu, S.; Zhang, W.; Chang, Q.; Yang, J.; Lin, K., A Chemical Method for Identifying the Photocatalytic Active Sites on Carbon Dots. Carbon 2016, 103, 391-393.

(9) He, G.; Lian, Z.; Yu, Y.; Yang, Y.; Liu, K.; Shi, X.; Yan, Z.; Shan, W.; He, H., Polymeric Vanadyl Species Determine the Low-Temperature Activity of V-Based Catalysts for the SCR of $\mathrm{NO}_{\mathrm{x}}$ with $\mathrm{NH}_{3}$. Sci. Adv. 2018, 4 (11), 4637. 
(10) Tang, S.; Cao, Z., Adsorption and Dissociation of Ammonia on Graphene Oxides: A First-Principles Study. J. Phys. Chem. C 2012, 116 (15), 8778-8791.

(11) Zhou, S.; Lin, S.; Guo, H., First-Principles Insights into Ammonia Decomposition Catalyzed by Ru Clusters Anchored on Carbon Nanotubes: Size Dependence and Interfacial Effects. J. Phys. Chem. C 2018, 122 (16), 90919100.

(12) Liu, T.; Ali, S.; Li, B.; Su, D. S., Revealing the Role of $\mathrm{sp}^{2} @ \mathrm{sp}^{3}$ Structure of Nanodiamond in Direct Dehydrogenation: Insight from DFT study. ACS Catal. 2017, 7 (6), 3779-3785.

(13) Marberger, A.; Ferri, D.; Elsener, M.; Krocher, O., The Significance of Lewis Acid Sites for the Selective Catalytic Reduction of Nitric Oxide on Vanadium-Based Catalysts. Angew. Chem. Int. Ed. 2016, 55 (39), 11989-11994.

(14) Jaegers, N. R.; Lai, J. K.; He, Y.; Walter, E.; Dixon, D. A.; Vasiliu, M.; Chen, Y.; Wang, C.; Hu, M. Y.; Mueller, K. T.; Wachs, I. E.; Wang, Y.; Hu, J. Z., Mechanism by which Tungsten Oxide Promotes the Activity of Supported $\mathrm{V}_{2} \mathrm{O}_{5}$ $/ \mathrm{TiO}_{2}$ Catalysts for $\mathrm{NO}_{\mathrm{X}}$ Abatement: Structural Effects Revealed by (51) V MAS NMR Spectroscopy. Angew. Chem. Int. Ed. 2019, 58 (36), 12609-12616.

(15) Topsoe, N. Y., Mechanism of the Selective Catalytic Reduction of Nitric Oxide by Ammonia Elucidated by InSitu Online Fourier-Transform Infrared-Spectroscopy. Science 1994, 265 (5176), 1217-1219.

(16) Kubota, H.; Toyao, T.; Maeno, Z.; Inomata, Y.; Murayama, T.; Nakazawa, N.; Inagaki, S.; Kubota, Y.; Shimizu, K.-i., Analogous Mechanistic Features of $\mathrm{NH}_{3}$-SCR over Vanadium Oxide and Copper Zeolite Catalysts. ACS Catal. 2021, 11180-11192.

(17) Lai, J.-K.; Wachs, I. E., A Perspective on the Selective Catalytic Reduction (SCR) of NO with $\mathrm{NH}_{3}$ by Supported $\mathrm{V}_{2} \mathrm{O}_{5}-\mathrm{WO}_{3} / \mathrm{TiO}_{2}$ Catalysts. ACS Catal. 2018, 8 (7), 6537-6551.

(18) Schuster, M. E.; Haevecker, M.; Arrigo, R.; Blume, R.; Knauer, M.; Ivleva, N. P.; Su, D. S.; Niessner, R.; Schloegl, R., Surface Sensitive Study to Determine the Reactivity of Soot with the Focus on the Europe-an Emission Standards IV and VI. J. Phys. Chem. A 2011, 115 (12), 2568-2580.

(19) Zhang, J.; Liu, X.; Blume, R.; Zhang, A.; Schloegl, R.; Su, D. S., Surface-Modified Carbon Nanotubes Catalyze Oxidative Dehydrogenation of n-butane. Science 2008, 322 (5898), 73-77. 